\title{
Natural and Unnatural Histories of the Pulmonary Vascular Circulation with a Ventricular Septal Defect (VSD)
}

\author{
KAZUOKI YOKOCHI, YOSHIHARU ETO, TAKATOSHI MIKAZIMA, HIROHISA KATO, \\ HIRONORI TOSHIMA*, FUMIHIKO UTSU** AND MICHIHIRO KOGA ${ }^{\dagger}$ \\ Department of Pediatrics, *Department of Internal Medicine, ${ }^{* *}$ Cardiovascular Research \\ Institute and ${ }^{+D e p a r t m e n t}$ of Surgery, Kurume University School of Medicine, \\ Kurume, 830 Japan
}

Received for publication November 1, 1983

\begin{abstract}
Summary: A total of 482 preoperative and 63 postoperative cases with VSD were catheterized to analyze their hemodynamic and pulmonary vascular status. Two different clinical courses are discussed depending upon the age of the patient. Either the $\mathrm{Rp} / \mathrm{Rs}$ ratio can be maintained within the normal range or otherwise can be progressively increased. The $\mathrm{Rp} / \mathrm{Rs}$ in the postoperative period tends to decrease in most cases. However a higher preoperative $\mathrm{Rp} / \mathrm{Rs}$ and an older age at surgry, leads to smaller decrements in the postoperative $\mathrm{Rp} / \mathrm{Rs}$. In 17 cases with a preoperative $\mathrm{Rp} / \mathrm{Rs}$ greater than $\mathbf{0 . 7 ,} 5$ fatalities and 12 survivors were found. There were 3 patients with "Eisenmenger complex" among the survivors. Pure oxygen was inhaled to examine the pulmonary vascular responsiveness. The patients with good oxygen responses before the operation had greater decrements in the postoperative Rp/Rs. 25 fatalities were found pre- and postoperatively. 9 patients, whose ages were less than 1 year were among 21 catheterized cases with $\mathrm{Qp} / \mathrm{Qs}$ greater than the 12 cases which were older than 1 year. However, the Rp/Rs under 1 year of age was signifi cantly less than that over 1 year of age. 9 fatalities in patients under 1 year of age had significantly higher $\mathrm{PaCO}_{2}$ levels than the survivors who were also under 1 year of age. It is concluded that infants who suffer from respiratory failure must be treated with surgical intervention. Corrective surgery may also be planned for other cases, when the preoperative $\mathrm{Rp} / \mathrm{Rs}$ is greater than 0.9 , except those who are older than 5 years and have failed to respond to oxygen and/or Tolazolin.
\end{abstract}

Key words: VSD - pulmonary vascular resistance - respiratory failure congestive heart failure - pulmonary obstructive disease

\section{Introduction}

The natural history of a ventricular septal defect (VSD) is influenced primarily by age, the size of the defect and the pulmonary vascular status. None of these factors should be ignored. In particular, the pulmonary vascular status may play an important role in determining the out- come in cases with large VSDs, where the pulmonary and systemic pressures are almost equal. Pulmonary hypertension in large sized VSDs is generally a consequence of excessive pulmonary arterial blood flows and pulmonary vascular obstructive changes.

VSD is one of the most common forms of congenital heart disease (CHD), and 
numerous publications relating to the hemodynamic changes and the indications for surgery have been reported in recent decades (Arcilla et al. 1963; Bloomfield, 1964; Blount et al. 1955; Lynfield et al. 1961; Hoffman 1965, 1968, 1970; Kidd et al. 1965). A general consensus has almost been reached for the clinical management of VSD. However fatal VSD cases are still encountered, thus the future management of VSD must be modified. Therefore a full analysis of all patients with VSD in our clinic during the last decade was performed to clarify the hemodynamic status and reevaluate the indications for surgery. The results of this study will be valuable for improving the management of VSD patients.

\section{Patients and Methods}

\section{Patients}

Of 1650 known cases of isolated VSD since 1972, 482 in which the diagnosis was confirmed by either cardiac catheterization or by autopsy were included in this study. The age ranged from one month to 51

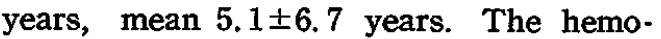
dynamics of each patient had been examined preoperatively, and 63 of these in which the pulmonary vascular resistance (PVR) was high preoperatively were examined by recatheterization, postoperatively.

\section{Cardiac Catheterizations}

Cardiac catheterizations were performed under ketamine anesthesia $(5 \mathrm{mg} / \mathrm{kg}$ intramuscularly) after sedation with $1 \mathrm{mg} / \mathrm{kg}$ pethidine hydrochloride (®Opistan) and 2 $\mathrm{mg} / \mathrm{kg}$ hydroxyzine hydrochloride (هAtalax-P) intracutaneously, in all cases under 5 years of age and in some cases over 5 years of age. Patients who responded well to treatment were anesthetized only locally using $1 \%$ procaine. Before 1974, catheters were usually inserted into the saphenous vein for right side catheterization and into the femoral artery for left side catheterization by a cut down method. Subsequent to 1974 , all cardiac catheterizations were performed with the percutaneous method. The oxygen saturation of each blood sample was measured with an oxymeter (AHSJAPAN, Japan). Oxygen consumption was assumed to be $180 \mathrm{ml} / \mathrm{min}$. multiplied by the body surface area (Rudolph, 1958). Intracardiac pressures were measured with a transducer (Siemens Elema, WG) connected to an 8 channel Mingography (Siemens Elema, WG). The pulmonary blood flow (Qp) and the systemic blood flow (Qs) were detarmined indirectly by Fick's principle. The pulmonary vascular resistance (PVR) was derived from $\mathrm{Qp} / \mathrm{Qs}$ divided by mean pulmonary pressure. The systemic vascular resistance (SVR) was derived from the mean aortic pressure minus the mean right atrial pressure and expressed in unit $/ \mathrm{m}^{2}$. PVR was represented by total PVR in most cases. the pulmonary to systemic vascular resistance ratio $(R p / R s)$ was employed as an indicator of pulmonary vascular resistance.

\section{Pulmonary vascular respsonsiveness}

Pure oxygen was inhaled through a face mask in cases of high PVR for 10 to 20 minutes to examine the responsiveness of the pulmonary vascular bed. Intrapulmonary injection of Tolazolin was also administered for the same purpose.

\section{Echocardiographic study}

Right ventricular systolic time intervals (RVSTI) using M-mode echocardiography were recorded consecutively to evaluate the postoperative changes in PVR. In patients with complete right bundle branch block, isometric contraction times (ICT) were used instead of pre-ejection period (PEP). The RVSTI was then calculated from RVPEP (RVICT)/RVET. 


\section{Statistics}

The data is expressed as mean \pm standard deviation, and analyzed by the Student's $t$-test or by the linear correlation coefficient. A probability less than 0.05 is considered significant.

\section{Results}

\section{Age factors on $R p / R s$}

The $\mathrm{Rp} / \mathrm{Rs}$ for all the cases are plotted in Fig. 1. Seven preoperative deaths and 14 postoperative deaths are included. Most values for $\mathrm{Rp} / \mathrm{Rs}$ are within the normal range. but some are high for the age. At less than 1 year of age, $\mathrm{Rp} / \mathrm{Rs}$ seldom exceeds 0.6. It is interesting that the cases with an $\mathrm{Rp} / \mathrm{Rs}$ greater than 1.0 are all over 2 years of age. Two clinical courses can account for these findings. Either the majority of cases have a $R p / R s$ ratio within the normal range, or alternatively, in the minority of cases $\mathrm{Rp} / \mathrm{Rs}$ increases in an age related manner. Most of the preoperative deaths occurred in patients under 1 year of age, and most of the postoperative deaths in patients over 1 year of age.

\section{Changes of postoperative $R p / R s$}

Sixty three cases were recatheterized postoperatively to evaluate the change in $\mathrm{Rp} / \mathrm{Rs}$. The $\mathrm{Rp} / \mathrm{Rs}$ ratio at the postoperative examination was less than the preoperative $\mathrm{Rp} / \mathrm{Rs}$ in most cases (Fig. 2). The postoperative $\mathrm{Rp} / \mathrm{Rs}$ returned to the normal range in those cases where the preoperative $\mathrm{Rp} / \mathrm{Rs}$ was within or slightly above the normal range. In those cases with a preoperative $R p / R s$ above 0.7 there was usually a decreased postoperative $R p /$ Rs, which was still within the upper normal or high range. The higher the preoperative $\mathrm{Rp} / \mathrm{Rs}$ was and the older the

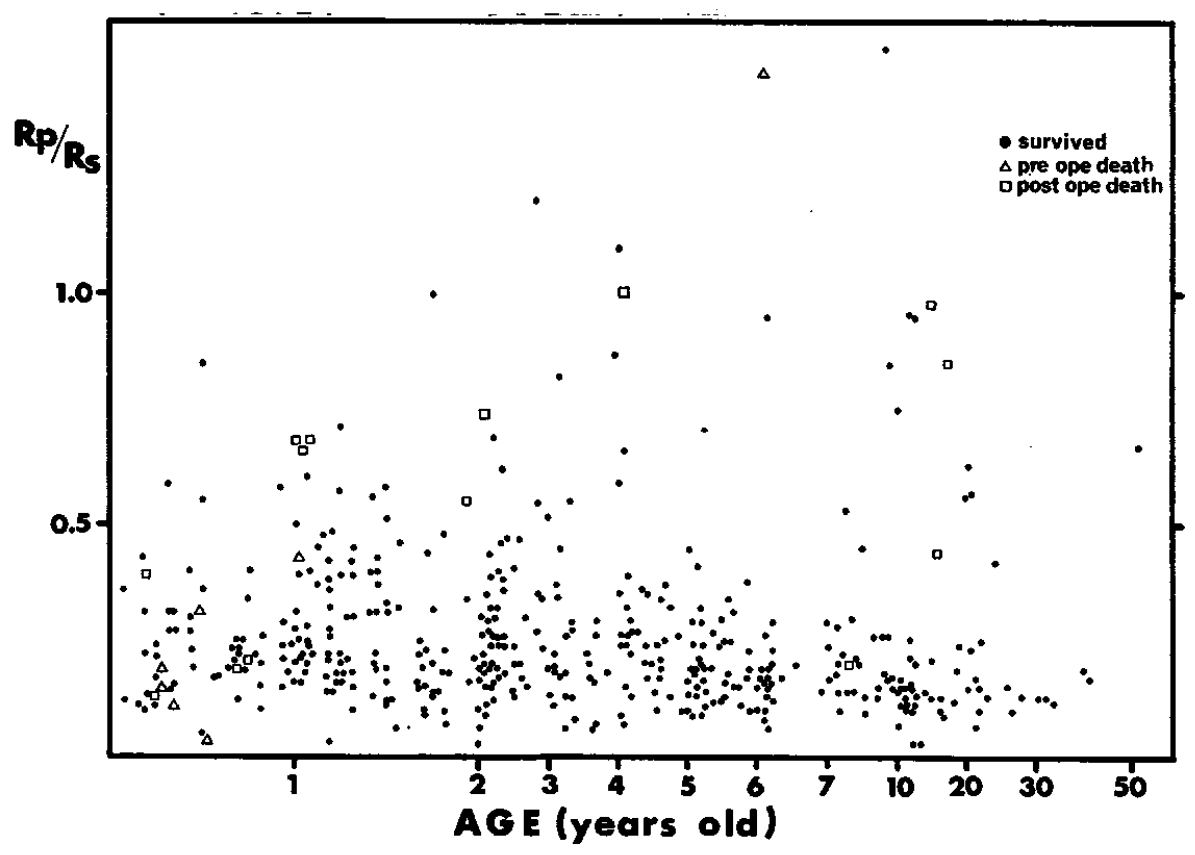

Fig. 1. Distribution of pulmonary vascular resistance according to age in 482 cases of isolated VSD. 


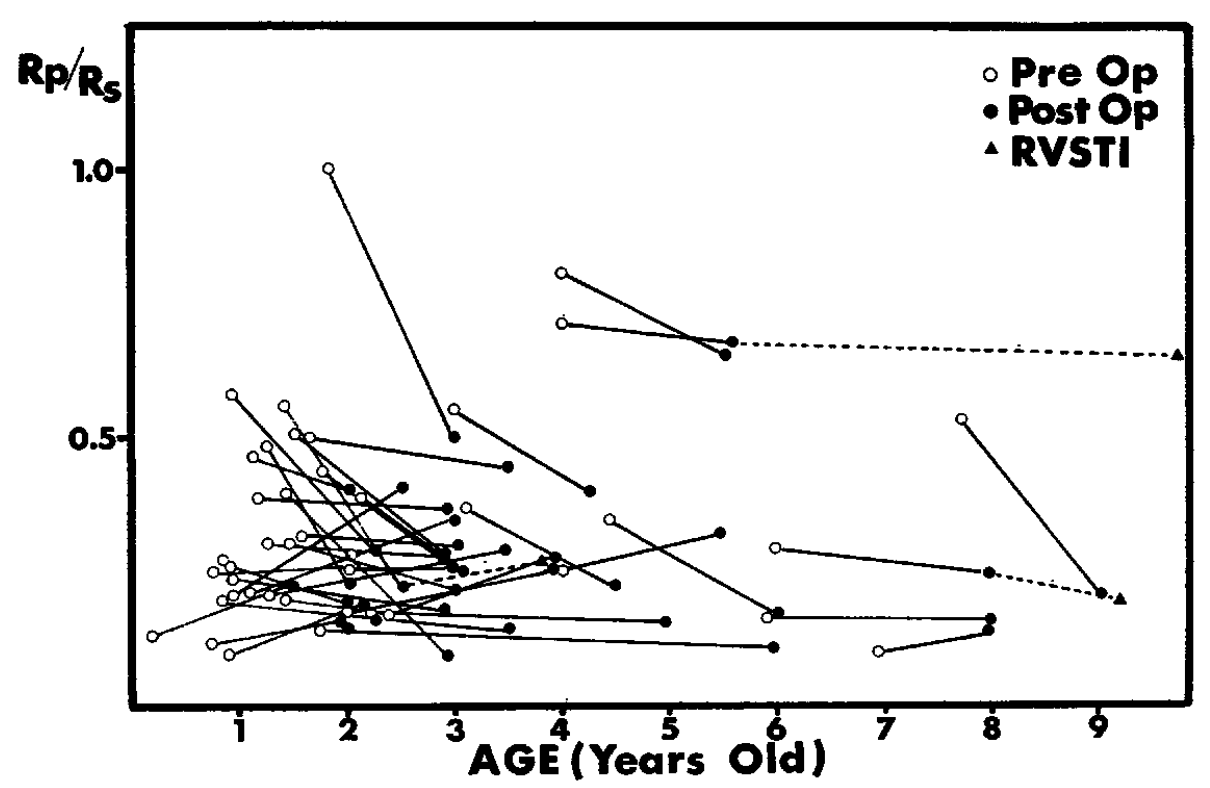

Fig. 2. Rp/Rs before and after surgery.

The dotted line shows the Rp/Rs which was estimated by RVSTI using M-mode echocardiography.

patient was at surgery, then the smaller the decrement was in postoperative $R p / R s$. Particularly in patients over 2 years of age, there was good correlation coefficient between the preoperative and postoperative $R p / R s(y=0.4 x+0.09, r=0.747)$ (Fig. 3).

\section{Outcomes in cases of high pulmonary vascular resistance}

Seventeen cases with $\mathrm{Rp} / \mathrm{Rs}$ exceeding 0.7 are entered in this category (Table 1 ). All except one were more than 1 year of age. Twelve patients entered surgery. Eight survived and 4 died during the early postoperative period. The other 5 patients were judged to be unsuitable for surgery. Three of these were diagnosed as "Eisenmenger complex". One non-operated case died suddenly at a later date. It should be added that the five deaths and four nonoperated cases were significantly older $(p=0.03)$ and had higher $\operatorname{Rp} / \operatorname{Rs}(p=0.003)$

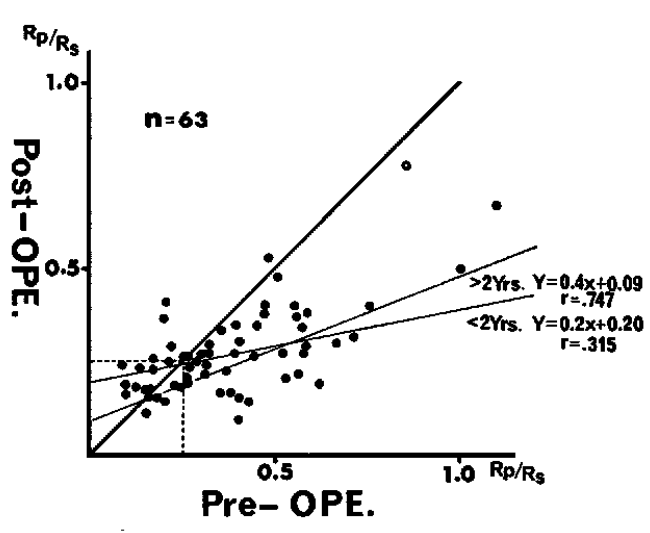

Fig. 3. Correlation between preoperative $\mathrm{Rp} / \mathrm{Rs}$ and postoperative $\mathrm{Rp} / \mathrm{Rs}$ at ages under or over 2 years.

than the 8 survivors.

IV. Pulmonary vascular responsiveness by $\mathrm{O}_{2}$ inhalation

A linear correlation coefficient was 
found between the magnitude of the drop in $R p / R s$ caused by inhalation of pure oxygen and the postoperative $R p / R s$ ( $y=$ $3.9 x-12.1, r=0.66$ ) (Fig. 4). This indicates that patients with a good oxygen response experienced a greater decrement in postoperative $\mathrm{Rp} / \mathrm{Rs}$.

\section{Fatal cases}

A total of 25 fatalities occurred preoperatively or postoperatively. Cardiac catheterizations were performed on 21 of these patients. The hemodynamic status of two age groups were compared (Fig. 5). The mean ratio of pulmonary to systemic blood flow, Qp/Qs, for those under 1 year of age was $4.5 \pm 1.8$. It was $1.6 \pm 1.0$ for those over 1 year of age. The $\mathrm{Qp} / \mathrm{Qs}$ for patients less than 1 year was significantly greater than the value for patients over 1 year of age $(p<0.001)$.

The mean $\mathrm{Rp} / \mathrm{Rs}$ was $0.19 \pm 0.11$ for the age group of less than 1 year and 0.70 \pm 0.36 for those over 1 year of age. Thus the $R p / R s$ is significantly higher after 1 year of age $(p<0.005)$.

The fatalities under 1 year of age had a greater pulmonary blood flow and lower
TABLE 1

Outcomes of high PVR cases (Rp/Rs $>0.7)$.
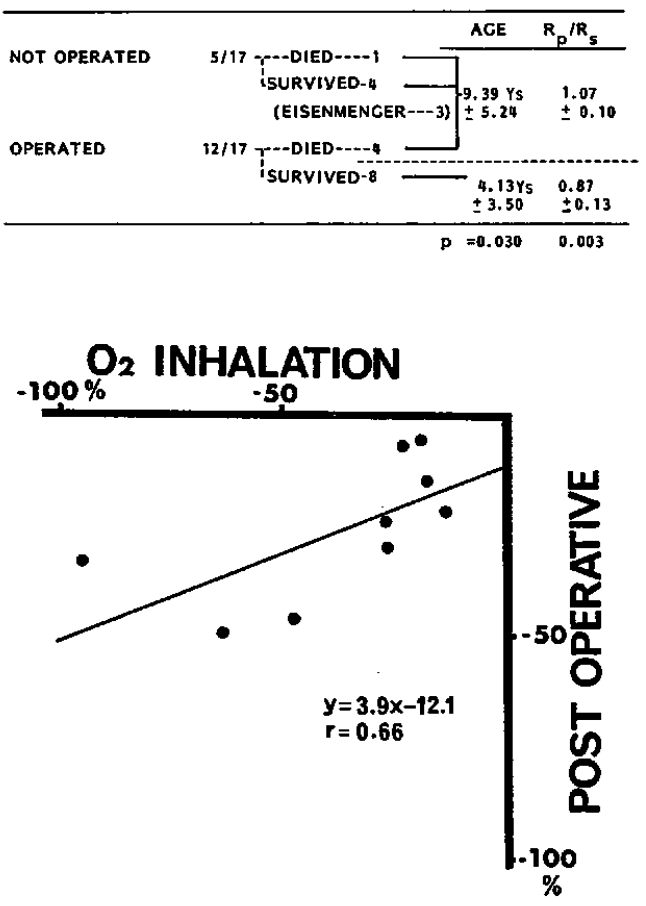

Fig. 4. Correlation of the decrement in $\mathrm{Rp} / \mathrm{Rs}$ after $\mathrm{O}_{2}$ inhalation and the postoperative status.

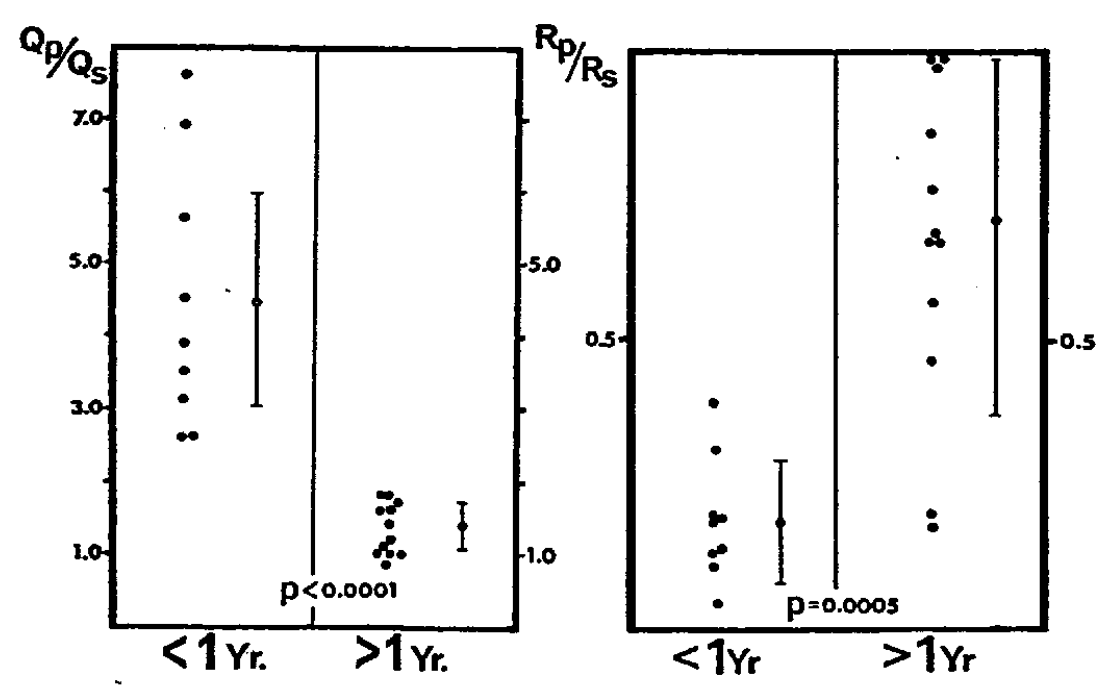

Fig. 5. $\mathrm{Qp} / \mathrm{Qs}$ and $\mathrm{Rp} / \mathrm{Rs}$ in terminal cases under and over 1 year of age. 
PVR than those over 1 year of age.

The $\mathrm{PaCO}_{2}$ levels in fatal cases under 1 year of age were compared to the levels in survivors under 1 year of age, to evaluate the respiratory status. The mean $\mathrm{PaCO}_{2}$ was $63.6 \pm 21.2 \mathrm{mmHg}$ in the fatal cases and $40.1 \pm 6.9 \mathrm{mmHg}$ in the survivors $(\mathrm{P}<0.001)$.

It is concluded that the infant fatalities are due to respiratory failure caused by high pulmonary blood flows.

\section{Discussion}

VSD is one of the most common forms of congenital heart disease (CHD), with an incidence of almost $50 \%$ of all $\mathrm{CHD}$ (Keith, 1978). Accordingly, the management and hemodynamics of this disorder have been well studied (Agosti, 1975; Arcinegas et al. 1980; Campbell, 1970; Collins et al. 1972; Kato, 1972; Momma, 1974; Rudolph, 1978; Sagara, 1979; Weidman et al. 1977).

As a result of these studies the natural history of VSD has been clarified and a general agreement on the therapy has been achieved. Corrective surgery of VSD is considered to be one of the most uneventful and safest procedures for teatment of CHD. Some fatalities, however, have been reported even at the present time. $25 \mathrm{fa}$ tal cases were encounered in the 482 cases in this study. In 21 cases where the hemodynamic status was examined, 14 postoperative deaths occurred at all ages, whereas 7 of the preoperative deaths occurred in the group of less than 1 year of age. The basis for these differences can be explained by an intractable congestive heart failue associated with respiratory distress which usually begins at an age of 1 to 2 months and becomes progressively worse until pulmonary vascular obstructive disease is produced. The respiratory failure may induce acidemia which can reduce myocardial function, and further aggra- vate the congestive heart failure. Thus a vicious cycle is established. Most of the cases involving preoperative deaths had hypercapnea which did not respond to conventional therapy. Most of these patients, who were experiencing respiratory failure, died after the corrective surgery. These results strongly suggest that surgery for such severe cases must be performed before any respiratory failure develops. There is some recent evidence that an enlarged pulmonary artery can compress the trachea, create aterectasis or emphysema and may be involved in the respiratory failure (Fig. 6). When these phenomena are discovered on the chest rentogenogram, bronchofibrography can be used to locate and observe the compression site. Then the compressing pulmonary artery can be moved toward the chest wall with strings during the corrective surgery. Another threat to the VSD patient is progressive pulmonary vascular obstructive disease which is described in detail by Heath and Edwards (1958). Although direct measurment of PVR must accurately reflect the status of the pulmonary vasculature, this measurement of PVR is not always practical. The calculated PVR derived from Fick's principle is generally used (Keith, 1978). However, if the oxygen consumption is not measured directly, then the accuracy of the calculated PVR is limited. The ratio of the pulmonary vascular resistance to the systemic vascular resistance is probably a better indicator of PVR.

The PVR in most cases of large sized VSD can decrease after birth and increase again at a later time. The critical period is near 2 years of age (Hoffman, 1966; Friedli, 1974). The data in this report indicates that the drop of PVR after surgery is related to the age at surgery and the preoperative PVR, particularly after 2 years of age. A higher preoperative PVR leads to a smaller postoperative PVR decrement. 


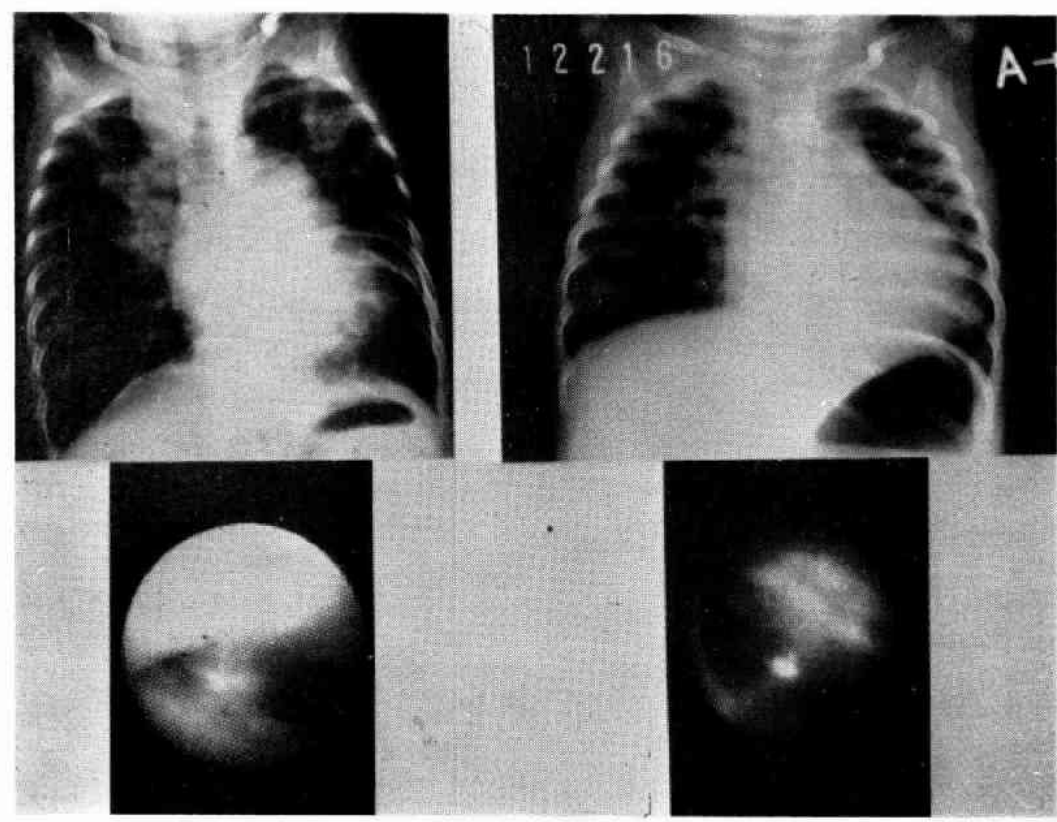

Fig. 6. A compressed right trachea is shown distally from the carina tracheae on the left. The compression was relieved by shifting the pulmonary artery during surgery. (right).

Thus it can be concluded that the patient with a high preoperative PVR and also with an age greater than 2 years should be scheduled for corrective surgery as soon as possible.

Another problem in the management of VSD is how to treat the patient whose PVR is already very high ( $R p / R s>0.7)$. In such circumstances, the PVR may be increased not only from pulmonary vascular obstructive disease but also from constriction of the pulmonary vasculature caused by hypoxemia and/or acidemia. To identify the responsible mechanism, inhalation of pure oxygen, or injection of Tolazolin, is usually performed during cardiac catheterization. Oxygen inhalation is preferred, because the injection of Tolazolin can cause systemic hypotension. Moreover the inhalation of oxygen may improve the patient's oxygenation. The magnitude of the drop in the $\mathrm{Rp} / \mathrm{Rs}$ by oxygen inhalation correlates with the drop of $\mathrm{Rp} / \mathrm{Rs}$ after surgery $(\mathrm{r}=0.66)$. These results indicate that a patient who responds well to oxygen has a good prognosis after surgery, even though the PVR is high. In contrast, a patient who does not respond well to oxygen should not undergo surgery. This is particularly true in patients of more than 5 years of age with an $\mathrm{Rp} / \mathrm{Rs}$ greater than 0.9 .

The basic principles for management of VSD should be: patients who have congestive heart failure should be treated with digitalis and diuretics, if needed. Once signs of respiratory failure appear, such as hypercapnea, patients should be scheduled for corrective or palliative surgery, as soon as possible. In patients with a preoperative $\mathrm{Rp} / \mathrm{Rs}$ exceeding 0.9 , the patients may be treated with corrective surgery, if they are younger than 5 years of age and have a good response to oxygen inhalation or Tolazolin injection. The only contraindication for corrective surgery is 
an age greater than 5 years, an $R p / R s$ greater than 0.9 , a failure to respond to oxygen, and a failure to respond to Tola zolin.

\section{References}

Agosti, J. and Subramanian, S. (1975). Corrective treatment of isolated ventricular septal defect in infancy. J. Pediatr. Surg. 10, 785-793.

Arcinegas, E., Farooki, Z. Q., Hakimi, M., Perry, B. L. and GreE, E.W. (1980). Surgical closure of ventricular septal defect during the first twelve months of life. Thorac. Cardiovasc. Surg. 80,921-928.

Arcilla, R. A., Agustsoon, M.H., Bicoff, J.P., WeinBerg, M. and GASUL, B. M. et al. (1963). Further observations on the natural history of isolated ventricular septal defects in in. fancy and childfood: serial cardiac catheterization studies in 75 patients. Circulation, 28, 560-771.

BloommField, D. K. (1964). The natural history of ventricular septal defect in patient surviving infancy. Circulation, 29, 914-955.

Blout, S. G., Muetler, H. and McCord, M.C. (1955). Ventricular septal defect: clinical and hemodynamic patterns. Am. J. Med. June, 871-882.

Blout, S. G. and Woodwark, G. M. (1960). Considerations involved in the selection for surgery of patient with ventricular septal defect. Am. J. Cardiol. February, 223-233.

CAMpBell, M. (1970). Natural history of ventricular septal defect. Br. Heart J. 33, 246257.

Collins, G., Calder, L., Rose, V., Kidd, L. and KeItH, J. D. (1972). Ventricular septal defect: clinical and hemodynamic changes in first five years of life. Am. Heart J. 84, 695-705.

FriendLI, B., Kidd, B.S. L., Mustard, W.T. and KeITH, J.D. (1974). Ventricular septal defect with increased pulmonary vascular resistance: late results of surgical closure. Am. J. Cardiol. 33, 403-409.

Heath, D. and Edwards, J.E. (1958). The pathology of hypertensive pulmonary vascular disease. A description of six grade of structural changes in the pulmonary arteries with special reference to congenital cardiac septal defects. Circulation, 18, 533-547.
Heath, D., Helmholz, F., Burchell, H. B., DvShane, J.W. and EDWARDS, J.E. (1958). Graded pulmonary vascular changes and hemodynamic findings in cases of atrial and ventricular septal defect and patent ductus arteriosus. Circulation, 18, 1155-1166.

HoffMAn, J. I. E. and Rudolph, A. M. (1965). The natural history of ventricular septal defects in infancy. Am. J. Cardiol. 16, 634-653.

Hoffman, J. E. and Rudolph, A.M. (1966). Increasing pulmonary vascular resistance during infancy in association with ventricular septal defect. Pediatrics, 38, 220-230.

Hoffman, J. I. E. (1968). Natural history of congenital heart disease: problems in its assessment with special reference to ventricular septal defects. Circulation, 37, 97-125.

HoffMAN, J. I.E. and RuDolph, A.M. (1970). The natural history of isolated ventricular septal defect: with special reference to selection of patients for surgery. Adv. Pediat. 17, 57-79.

Kato, H., Hirose, M., FuKuda, H. and Nagayama, T. (1972). Natural history of ventricular septal defect. Jpn. Circulat. J. 36, 814-818.

KeITH, J.D., Rowe, R.D. and VlaD, P. (1978). Heart disease in infancy and childfood, Third edn., p. 320. N. Y.: Macmillan Publishing Co.

Kidd, L., Rose, V., Collins, G. and Keith, J. (1965). The hemodynamics in ventricular septal defect in childhood. Am. Heart J. 70, 732-738.

Lynfield, J., Gasul, B. M., Arcilla, R. and Luan, L.L. (1961). The natural history of ventricular septal defects in infancy and childhood: based on serial cardiac catheterization studies. Am. J. Med. March, 357-371.

Momma, K. and TaKaO, A. (1974). The insidence and progerssion of pulmonary vascular obstructive disease in ventricular septal defect. Shinzo, 6, 1411-1417. (in Japanese)

Rudolph, A. M. and CAYler, G. G. (1958). Cardiac catheterization in infants and children. Clin. North Am. 5, 907.

RuDolpH, A.M. (1978). Ventricular septal defect-to operate or not. In Pediatric Cardiology 1977, ed. Anderson, R.H. and Shinebourne, E. A., p. 140. Livingstone: N.Y.: Churchill.

SAGARA, Y. (1979). Surgical results of ventricular septal defect with pulmonary hypertension. Kurume Med. J. 42, 265-285.

Weidman, W.H., Blount, S. G., DuShane, J.W., Gersony, W. M., Hayes, C. J. and Nadas, A.S. (1977). Clinical course in ventricular septal defect. Circulation, Supp I, 56-69. 